\title{
Correction to: The Importance of Viscous and Interfacial Forces in the Hydrodynamics of the Top-Submerged-Lance Furnace
}

\author{
D. OBISO, S. KRIEBITZSCH, M. REUTER, and B. MEYER
}

https://doi.org/10.1007/s11663-019-01717-7

(C) The Minerals, Metals \& Materials Society and ASM International 2019

\section{Correction to:}

Metallurgical and Materials Transactions B

Volume 50B, October 2019-2403

https://doi.org/10.1007/s11663-019-01630-z

THE article The Importance of Viscous and Interfacial Forces in the Hydrodynamics of the Top-Submerged-Lance Furnace, written by Obiso et al was originally published electronically on the publisher's internet portal on July 3, 2019 without open access.

With the author(s)' decision to opt for Open Choice the copyright of the article changed on October 3, 2019 to (C) The Author(s) 2019 and the article is forthwith distributed under a Creative Commons Attribution 4.0 International License (https://creativecommons.org/ licenses/by/4.0/), which permits use, sharing, adaptation, distribution and reproduction in any medium or format, as long as you give appropriate credit to the original author(s) and the source, provide a link to the Creative Commons licence, and indicate if changes were made.

Publisher's Note Springer Nature remains neutral with regard to jurisdictional claims in published maps and institutional affiliations.

D. OBISO and S. KRIEBITZSCH are with the CIC VIRTUHCON, Technische Universität Bergakademie Freiberg, Fuchsmühlenweg 9, 09599 Freiberg, Germany. Contact e-mail: sebastian.kriebitzsch@iec.tu-freiberg.de M. REUTER is with the Helmholtz Institute Freiberg for Research Technology, Chemnitzer Straße 40, 09599 Freiberg, Germany. B. MEYER is with the Chair of Energy Process Engineering and Thermal Waste Treatment, Technische Universität Bergakademie Freiberg, Fuchsmühlenweg 9, 09599 Freiberg, Germany.

The original article can be found online at https://doi.org/10.1007/ s11663-019-01630-z.

Article published online October 10, 2019. 